\title{
A Synergistic Materials Characterization Approach for the Evaluation of Particles and Talc Minerals in Cosmetic Powders
}

\author{
Ana C. Bohórquez, Kristy Schepker, Gary W. Scheiffele and Luisa Amelia Dempere* \\ Research Service Centers (RSC), Herbert Wertheim College of Engineering, University of Florida, \\ Gainesville, FL, USA. \\ * Corresponding author: ademp@eng.ufl.edu
}

In the cosmetics industry, safety concerns have increased lately due to the toxicity, and potential negative effects of nanomaterials and asbestos fibers, recently found in cosmetic talc products. These findings are creating significant public awareness of this lightly regulated industry $[1,2]$. Thus, the main objective of this preliminary study was to demonstrate the application of electron microscopy and microanalysis techniques, $\mathrm{x}$-ray powder diffraction analysis, and particle characterization techniques to assess the presence of nanomaterials and talc-asbestiform minerals in cosmetic formulations, using samples of facial powders.

Nanomaterials cover a size range between $1 \mathrm{~nm}$ to $100 \mathrm{~nm}$ exhibiting different physicochemical properties, or biological effects compared to bulk materials. The Federal Drug Administration (FDA) monitors the use of nanomaterials in cosmetics even though it does not have a legal definition for nanotechnology [3]. This compromises an accurate safety assessment in cosmetic powder formulations, in which formulations require control and measurement of particle size. Talc is composed of a wide range of mineralogical compounds and it is used in cosmetic powders to prevent caking and absorb moisture. The combination of electron microscopy and microanalysis techniques, x-ray diffraction and particle characterization techniques can determine the presence of nanoscale materials and distinguish the presence of asbestos versus fiber-shaped particles with similar appearance.

Tests were conducted with six randomly selected facial powder formulations purchased online. The facial powders were cosmetic products ranging from powder foundation, blush, and eye shadow. Scanning electron microscopy (SEM) and x-ray diffraction results show that most particles are larger than $10 \mu \mathrm{m}$ and have a wide variety of particle shape with no evidence of asbestos fibers. Laser diffraction analysis were able to verify a wide particle size distribution between $10 \mu \mathrm{m}$ to $67 \mu \mathrm{m}\left(\mathrm{D}_{50}\right)$. The facial powders used in this study show a low surface area and high hydrophobicity base on nitrogen adsorption at $77 \mathrm{~K}$ and water sorption at $273 \mathrm{~K}$ measurements. Low surface area results show good agreement with the presence of non-porous particles larger than $10 \mu \mathrm{m}$. The negligible amount of adsorbed water may correlate with non-existence of talc contaminated with asbestos fibers since water is known to adsorb on the surface of the fibers [4]. Because of the possibility of the inhalation of particles contained in facial powders, formulations may exhibit toxicity effects as a function of their surface area and chemical reactivity. Therefore, microsized particles in comparison with nanosized materials lead to a minimal surface area and water reactivity that is more likely to avoid a biological response.

It is suggested that the cosmetic powders evaluated in this study are safe because their particle size was found to be at the micron size range and asbestos fiber free, based on the combined materials characterization approach developed for facial powder assessment. The combined characterization approach proposed here provides precise information about particle size/shape/reactivity, and identifies mineralogical and chemical components crucial for the safety assessment of the facial powders. 
References:

[1] JS Pierce et al., Inhalation Toxicology 29 (2017), p. 443.

[2] AN Rohl et al., Journal of Toxicology and Environmental Health 2 (1976), p. 255.

[3] U.S. Food \& Drug Administration.

https://www.fda.gov/Cosmetics/ScienceResearch/Nanotech/ucm209177.htm (accessed February 21, 2019).

[4] JS Pierce et al., Clays and Clay Minerals 29 (1981), p. 161.
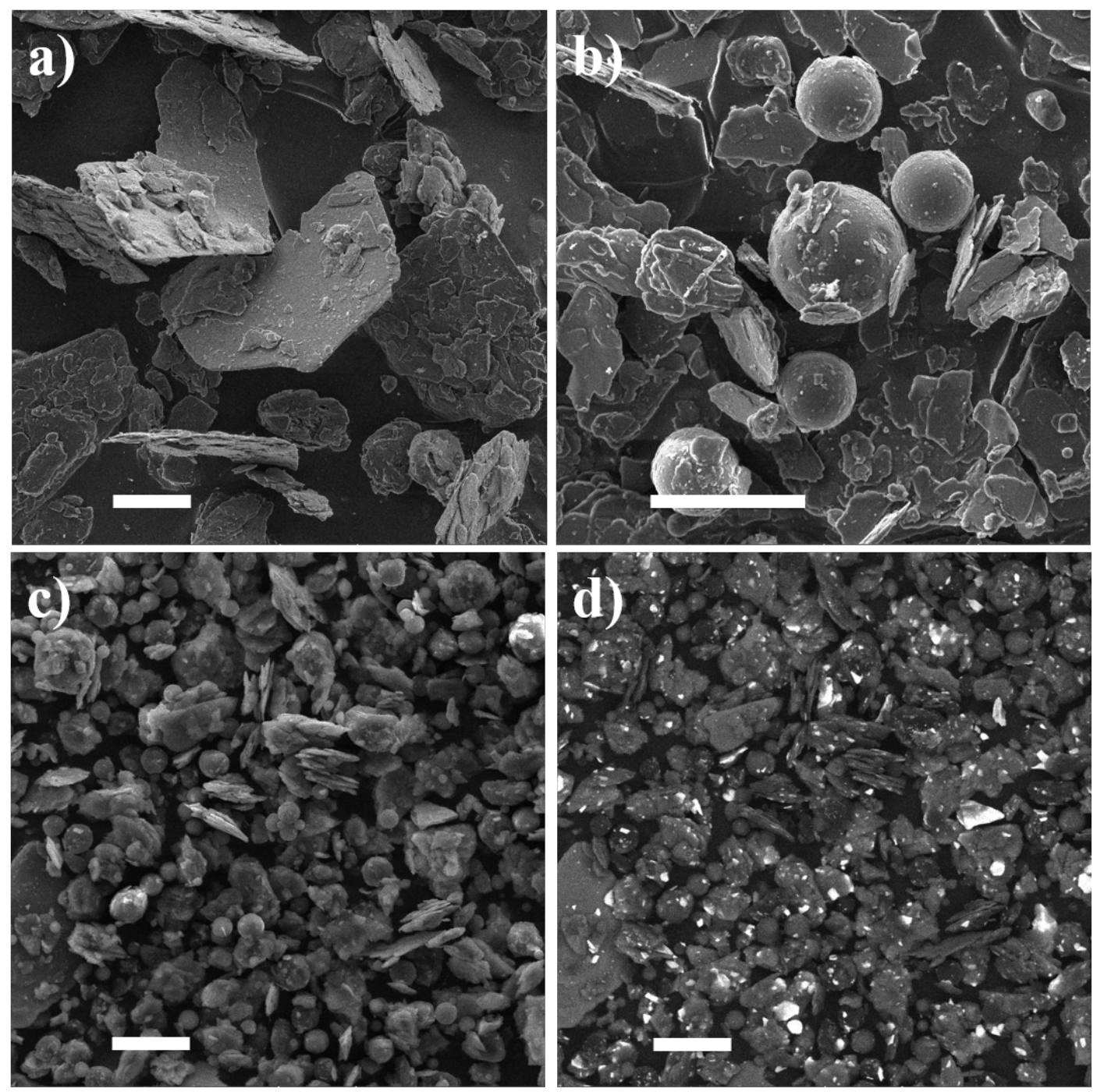

Figure 1. Representative SEM images for facial powders used in this study. (a) SEM image of an eye shadow sample (b) SEM image of a power foundation sample (c-d) Secondary electron versus backscattering electron (BSE) images of a finishing powder sample. Energy dispersive x-ray spectroscopy and $\mathrm{x}$-ray powder analysis suggest the presence of bismuth oxide chloride in the evaluated finished powder sample. Scale bar $20 \mu \mathrm{m}$. 